S. Chen · D. Lu • M. Zhang $\cdot$ J. Che $\cdot$ Z. Yin •

S. Zhang $\cdot$ W. Zhang $\cdot$ X. Bo $\cdot$ Y. Ding $\cdot$ S. Wang

\title{
Double-antigen sandwich ELISA for detection of antibodies to SARS-associated coronavirus in human serum
}

Published online: 17 August 2005

(C) Springer-Verlag 2005

\begin{abstract}
The study presented here was conducted to evaluate the performance of a double-antigen sandwich ELISA to detect antibodies in human serum against the coronavirus associated with severe acute respiratory syndrome (SARS). A recombinant partial nucleocapsid protein of SARSassociated coronavirus was used as a serodiagnostic antigen in the ELISA. A total of 2892 clinical serum samples were tested with the ELISA kit, which positively identified 25 of $35(71.4 \%)$ samples of patients with confirmed SARS infection, 286 of 407 (70\%) samples of patients suspected of having SARS, 229 of $302(75.8 \%)$ samples of convalescent SARS patients, and 0 of 544 samples obtained from healthcare workers; only 1 of 1604 clinical samples obtained from patients with other diseases demonstrated a weakly positive result. These results indicate that the double-antigen sandwich ELISA is an effective screening method for the serodiagnosis of SARS-associated coronavirus.
\end{abstract}

\section{Introduction}

An unusual atypical pneumonia that originated in Foshan, Guangdong Province, in mainland China in November 2002, has traveled more widely, swiftly, and lethally than any other recent new disease so far. Near the end of June 2003, a total of 8456 cases had been identified in 30 countries and areas, and 809 of them had resulted in death. The previously unknown disease was named severe acute respiratory syndrome (SARS) by the World Health Organization, and a novel coronavirus (SARS-CoV) was identified as the causative agent [1].

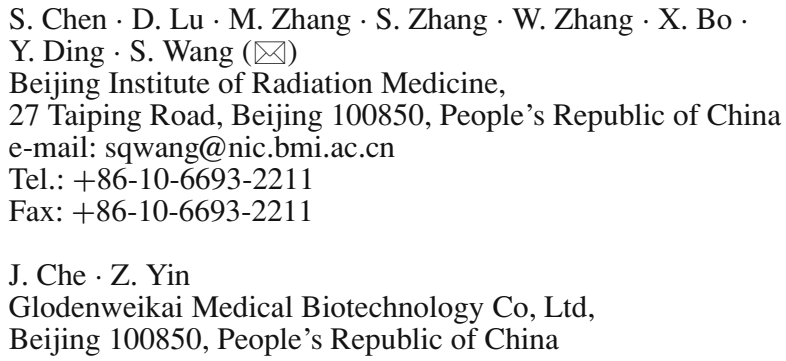

Coronaviruses are a family of enveloped single positivestranded RNA viruses that cause disease in humans and animals, but the other coronaviruses that are known to affect humans cause only the common cold [2]. Determination of the complete genome sequence of SARS-CoV identified the cause of the new disease, and bioinformatic analyses and sequence comparisons showed that SARS-CoV is not closely related to any of the other previously characterized coronaviruses, demonstrating an approximate identity of only $60 \%$ with other known coronaviruses [1]. SARS$\mathrm{CoV}$ is about 28,000 nucleotides in length and has at least 11 open reading frames encoding the replicase, 4 structural proteins (including spike, envelope, membrane, and nucleocapsid), and several other proteins with unknown functions [3].

The nucleocapsid protein is one of the major structural proteins of the virus. Previous research showed it has a variety of functions, including participation in the transcription and replication of viral RNA, and interference with cell cycle processes of host cells [4]. Moreover, in many coronaviruses, the nucleocapsid protein has high immunogenic activity and is abundantly overexpressed during infection [5]. All of these factors suggest that the nucleocapsid protein may be a potential source of a diagnostic antigen for detecting SARS infection, and many diagnostic methods have been developed based on the nucleocapsid protein [6-11]. In order to develop a recombinant protein for use as the coated antigen and enzyme-conjugated antigen in an enzyme-linked immunosorbent assay for the detection of antibodies to SARS-CoV, we used the expression and purification of a partial nucleocapsid protein of SARSassociated coronavirus. The double-antigen sandwich assay we developed was then used to test 2892 clinical serum samples, and the results are presented here.

\section{Materials and methods}

Serum samples were collected from the following groups of individuals and hospitals: 450 patients categorized as confirmed or suspected SARS cases and 302 convalescent 
individuals at the General Hospital of Chinese People's Liberation Army (PLA), the 302 Army Hospitals of PLA, the 309 Army Hospitals of PLA, the Sino-Japan Friendship Hospital, and the Yongdinglu Hospital during a SARS outbreak in Beijing, China, between April and June 2003; 1596 patients with other diseases at the General Hospitals of Chinese PLA; and 544 healthcare workers who had close contact with SARS-infected patients at the XiaoTangShan Hospital, which receives SARS cases.

Total RNA of SARS-CoV was kindly provided by the Zhejiang province branch of the Centers for Disease Control and Prevention, and the Thermoscript RT-PCR system (Invitrogen, San Diego, CA, USA) was used to obtain nucleocapsid gene according to the manufacturer's instructions. Forward primer NF1 (5'GCGGATCCAGCGGAGGTGGTGAAACTGCC-3') (the underlined sequence represents the BamHI site) and reverse primer NR1 (5'-CCGAATTCTTATGCCTGAGTT GAATC- $3^{\prime}$ ) (the underlined sequence represents the EcoRI site) were designed to amplify this gene. Another reverse primer, NR2 (5'-CCGAATTCTTA CTTCTTCTTCTTTGCCTGAGTTGAATC-3') (the sequence in bold and italic type was added to NR1), was also designed based on NR1 to add four lysines to the $\mathrm{C}$-terminal of the recombinant protein. The amplified nucleocapsid gene products were then purified using the Wizard PCR Purification kit (Promega, Madison, WI, USA) followed by digestion with EcoRI and BamHI (Takara, Tokyo, Japan). The products amplified with the two pairs of primers (NF1+NR1 and NF1+NR2) were named $\mathrm{N}$ and $\mathrm{N}-4 \mathrm{~K}$, respectively.

For the expression of nucleocapsid recombinant protein, the digested DNA fragments were subsequently cloned into pGEX 4T-1 GST fusion vector (Amersham Pharmacia Biotech, Piscataway, NJ, USA) at the BamHI and EcoRI sites. The recombinant clones were identified by PCR and confirmed by sequencing, and the right recombinant plasmid was transformed into BL21 (DE3; Novagen, Madison, WI, USA) for expression of the nucleocapsid protein. A freshly isolated colony was chosen and incubated overnight at $37^{\circ} \mathrm{C}$ in liquid Luria-Bertani medium containing ampicillin $(100 \mu \mathrm{g} / \mathrm{ml})$. The overnight culture was diluted to 1:200 in fresh medium and incubated further at $37^{\circ} \mathrm{C}$ until the optical density (OD) of the culture, measured at $600 \mathrm{~nm}$ (OD600), reached 0.6-0.8. Then, $0.5 \mathrm{mM}$ isopropyl-b-D-thiogalactopyranoside was added to the culture, and growth was continued at $37^{\circ} \mathrm{C}$ for the next $2 \mathrm{~h}$. The purification of the fusion protein was performed using glutathione Sepharose 4B (Amersham Pharmacia Biotech) according to the manufacturer's specifications. The protein concentration was determined according to the Lowry method.

The purified recombinant protein and protein extracts of the induced recombinant cells were resuspended in $1 \%$ sodium dodecyl sulfate (SDS), $10 \mathrm{mM}$ Tris- $\mathrm{HCl}, \mathrm{pH}$ 8.0, $5 \%$ 2-mercaptoethanol and boiled for $3 \mathrm{~min}$; they were then subjected to electrophoresis on $12 \%$ SDS-polyacrylamide gels. The gels were then stained with Coomassie-blue R250 (Amersham Pharmacia Biotech). For Western blot- ting, protein was transferred to polyvinylidene diflouride membrane by electrotransfer. After transfer, the polyvinylidene diflouride membrane (Sigma, St. Louis, MO, USA) was blocked in blocking buffer, phosphate-buffered saline (PBS) supplemented with 10\% dry skimmed milk (PBSM), for $30 \mathrm{~min}$ at room temperature. After blocking, the membrane was incubated with antiserum from mouse vaccinated with the inactivated SARS coronavirus diluted 1:100 in PBSM for $3 \mathrm{~h}$. A negative control was also set to incubate with serum from a healthy individual. The bound antibodies were detected using horseradish peroxidase (HRP)conjugated anti-goat IgG (Sigma) and peroxidase activity was revealed using the ECL kit (Amersham Pharmacia Biotech).

HRP-conjugated antigen was prepared according to the procedure developed by Nakane and Kawaoi and modified by Wilson and Nakane [12]. For the removal of unconjugated HRP, the conjugated solution was subjected to a Sephadex G200 column (Amersham Pharmacia Biotech). The binding capacity (i.e., the mole rate of HRP to antigen) of the HRP-conjugated antigen was analyzed using calculated OD405/OD280 values [13], and the valence of the HRP-conjugated antigen was determined by checkerboard titration.

The optimal concentration of antigen conjugates was determined using checkerboard titration. The wells of microtiter plastic plates (NunC, Roskilde, Denmark) were coated with $40 \mathrm{ng}$ of glutathione sulfotransferase-N protein in $100 \mu \mathrm{l}$ of $50 \mathrm{mM}$ carbonate buffer (pH 9.6). After overnight incubation at $4^{\circ} \mathrm{C}$, the wells were washed three times with PBS containing $0.05 \%$ Tween 20 and blocked with $150 \mu \mathrm{l}$ of $0.25 \%$ bovine serum albumin dissolved in $0.01 \mathrm{~mol} / \mathrm{l} \mathrm{PBS}\left(\mathrm{pH} \mathrm{7.4)}\right.$ ) for $4 \mathrm{~h}$ at $37^{\circ} \mathrm{C}$. The wells were again washed three times with PBS containing $0.05 \%$ Tween 20 and dried at room temperature for $8 \mathrm{~h}$. For sample detection, $50 \mu 1$ sera and $50 \mu 1 \mathrm{HRP}$-conjugated antigen were added to each well. A negative and a positive control was included on each plate. After incubation for $60 \mathrm{~min}$ at $37^{\circ} \mathrm{C}$, followed by three rounds of washing, $100 \mu \mathrm{l}$ of TMB (3,3,5,5'-tetramethylethylenediamine) (Sigma) substrate solution was added and the plates were incubated for $10 \mathrm{~min}$ at $37^{\circ} \mathrm{C}$. The color reaction was stopped by the addition of $50 \mu \mathrm{l}$ of $4 \mathrm{M}$ sulfuric acid, and the OD450 was determined using a microplate reader (MK3; Thermo Labsystem, Helsinki, Finland).

Real-time (RT)-PCR to detect SARS-CoV was performed as described previously [14]. RT-PCR was performed in a $20-\mu 1$ volume of a final mixture containing $5 \mu \mathrm{l}$ of RNA, $10 \mathrm{mM}$ of Tris- $\mathrm{HCl}(\mathrm{pH} 8.3), 50 \mathrm{mM}$ of $\mathrm{KCl}$, $4 \mathrm{mM}$ of $\mathrm{MgCl}_{2}, 300 \mathrm{nM}$ of fluorescent probe and quencher probe, $0.5 \mu \mathrm{M}$ of each of both primers, $200 \mu \mathrm{M}$ (each) of dATP, dCTP, and dGTP, $400 \mu \mathrm{M}$ of dUTP, $2 \mathrm{U}$ of avian myeloblastosis virus reverse transcriptase (Promega), and $1 \mathrm{U}$ of Taq DNA polymerase (Promega). The thermal cycling conditions were $42^{\circ} \mathrm{C}$ for $50 \mathrm{~min}, 94^{\circ} \mathrm{C}$ for $10 \mathrm{~min}$, and 50 cycles of $94^{\circ} \mathrm{C}$ for $10 \mathrm{~s}, 55^{\circ} \mathrm{C}$ for $20 \mathrm{~s}$ and $72^{\circ} \mathrm{C}$ for $10 \mathrm{~s}$ using the iCycler iQ real-time PCR detection system (BioRad). Real-time detection was performed at the annealing temperature of each cycle. 


\section{Results and discussion}

The primers were designed to amplify the second half of the nucleocapsid gene, from 637 to $1269 \mathrm{nt}$, with the expected size being about $603 \mathrm{bp}$. As analyzed by agarose gel electrophoresis, the partial nucleocapsid gene product with the expected size was obtained. The purified PCR products were digested with BamHI and EcoRI and cloned into pGEX-4T-1 in order to obtain a glutathione-S-transferase (GST) fusion protein. Plasmids were transformed into Escherichia coli BL21 (DE3) for expression of GST-N and GST-N-4K fusion proteins. Recombinant clones were identified by PCR and the plasmid with the correct size was further confirmed by sequencing. The nucleotide sequence and deduced amino acid sequence are available at GenBank under accession number NC004718.

Recombinant nucleocapsid proteins were successfully expressed in E. coli as fusion proteins with GST-N and GST-N-4K. The protein extracts of the induced recombinant cells and the purified recombinant nucleocapsid proteins were analyzed using 12\% SDS-polyacrylamides gels and Coomassie blue staining. The expressed nucleocapsid fusion proteins each had an approximate molecular mass of $49 \mathrm{kDa}$, in accordance with the expected size of the fusion proteins, and they were highly expressed in E. coli, with the amount of the fusion protein being about $37 \%$ of the total protein of the cell lysates. When the fusion proteins are purified with glutathione-Sepharose 4B, the purity of the recombinant nucleocapsid protein can reach $95 \%$. Following Western blot analysis with antiserum from mouse vaccinated with inactivated SARS-CoV, the purified fusion proteins reacted strongly and specifically with antiserum, and no nonspecific band was shown in the negative control. This indicated that four more lysines in the C-terminal of GST-N-4K does not affect the antigenicity of GST-N-4K.

To prepare HRP-antigen conjugates with high activity for the sandwich ELISA, GST-N and GST-N-4K were coupled with HRP, and a HRP-antigen conjugate with high activity was chosen from them. The activity of the conjugate was determined by the mole ratio of HRP to antigen and the valence of the conjugate. As calculated by OD405/OD280, the mole ratio of GST-N-HRP conjugate was $0.98 \pm 0.08$, while that of GST-N-4K-HRP conjugate was $1.45 \pm 0.16$. The $p$ value was calculated as 0.021 using Student's $t$-test, which showed that the binding capacity of GST-N-4K-HRP conjugate was better. The valence of GST-N-HRP and GST$\mathrm{N}-4 \mathrm{~K}$-HRP, as determined by checkerboard titration, was 1:500 (about $1 \mu \mathrm{g} / \mathrm{ml}$ ) and 1:1000 (about $0.5 \mu \mathrm{g} / \mathrm{ml}$ ), respectively. Since the results indicated that GST-N-4K-HRP conjugate was better for the sandwich ELISA, this conjugate was used in the ELISA. HRP reacted with primary amine in the antigen, and the number of primary amines can affect the efficiency [13]. In order to increase the binding capacity of antigen to HRP, the antigen GST-N-4K was designed, which has four more lysines in the C-terminal than GST-N. The four extra lysines increased the number of primary amines, and GST-N-4K showed a higher binding capacity than GST-N in the reaction with HRP.
The optimum concentration of coated antigen and dilution fold of HRP-conjugate antigen for ELISA were determined by checkerboard serial-dilution analysis. The same positive and negative serum samples were used in the analysis. Combinations that gave the highest $\mathrm{P} / \mathrm{N}$ ratios $(\mathrm{OD}$ positive control/OD negative control) were determined as optimal. The results showed that $40 \mathrm{ng} /$ well of antigen combined with 1:1000 diluted conjugate gave the highest $\mathrm{P} / \mathrm{N}$ ratio of $126.27 \pm 3.15$.

To determine the optimal OD cutoff value for the ELISA assay to allow discrimination between samples positive and negative for SARS, 616 human sera from healthy individuals were tested with the ELISA (data not shown). The mean $\mathrm{OD}(\mathrm{X})$ and standard deviation (SD) values were calculated as 0.050 and 0.0333 , respectively. A cutoff value of 0.15 was acquired by calculating $\mathrm{X}+3 \mathrm{SD}$.

To investigate the specificity and sensitivity of the ELISA assay, a panel set up by the National Institute for the Control of Pharmaceutical and Biological Products in Beijing, China, was employed; it included 18 positive sera, 20 negative sera, and 1 serially diluted serum as a sensitivity control (which tested positive at a maximum dilution of 1:4, as assayed by immunofluorescent and indirect ELISA with virus lysates as antigen). Each of the 18 positive sera produced an OD between 0.354 and 2.398, all of which were greater than the cutoff point, and all 20 negative sera gave an OD below $0.15(0.058 \pm 0.030)$. Moreover, when the sensitivity control serum was diluted to $1: 64$, it gave an OD of 0.162 . The results proved the ELISA is a sensitive and specific method for the detection of SARS-CoV antibodies.

Repeatability of the sandwich ELISA for intra- and interassay precision was assessed using 10 positive qualitycontrol sera. The coefficient of variation range was 3.0 $4.1 \%$ for intra-assay precision and $3.6-4.4 \%$ for inter-assay precision, indicating the ELISA is a specific, sensitive, and repeatable method.

To further investigate the performance of the sandwich ELISA, samples from SARS-confirmed and -suspected patients, convalescent individuals, patients with other diseases and healthcare workers were analyzed. The results are summarized in Table 1. The single positive result found among the 1490 patients with other diseases was detected with an OD of 0.21. Analysis of these results obtained with clinical samples reveals good specificity of the ELISA.

Table 1 Results obtained using the double-antigen sandwich ELISA to detect SARS in clinical samples

\begin{tabular}{lll}
\hline Patient type & $\begin{array}{l}\text { No. of samples } \\
\text { tested }\end{array}$ & $\begin{array}{l}\text { No. }(\%) \\
\text { positive }\end{array}$ \\
\hline Recovering from SARS & 302 & $229(75.8)$ \\
Confirmed SARS & 35 & $25(71.4)$ \\
Probable SARS & 407 & $286(70.2)$ \\
Probable SARS but excluded & 8 & 0 \\
Non-SARS with respiratory illness & 22 & 0 \\
Non-SARS with fever & 84 & 0 \\
Healthcare worker & 544 & 0 \\
Other disease & 1490 & $1(0.07)$ \\
\hline
\end{tabular}


Although the percentage of samples that tested positive with the ELISA was about $70 \%$, this may be due to the inclusion of some samples from patients who had been misdiagnosed with SARS. During the SARS outbreak, misdiagnosis occurred frequently in efforts to prevent further spread of the disease. Among the specimens from patients suspected of having SARS, some may have been collected from patients who were not actually infected. Unfortunately, it was not possible for us to follow up all of those patients and their samples, which were collected at various times during the outbreak; thus, we are not sure how many patients in this group were eventually excluded. However, the eight cases we knew were excluded and were placed in a separate group, and the ELISA produced negative results for all of these patients.

Only 25 of the 35 SARS-confirmed cases were detected by the ELISA. This may be due to low antibody titers in the ELISA-negative patients. The World Health Organization has reported that tests to detect SARS-CoV might be positive as early as 8-10 days after the onset of illness and often by day 14, but sometimes a positive result is not achieved until 28 days after illness onset [15]. For the 35 cases we tested, 7 samples were collected from patients who had been ill for less than 10 days, and only 2 of these were weakly positive, whereas all of the samples from patients who had been ill for more than 25 days were positive. While the number of cases is too small for statistical analysis, our results are, to a certain extent, in accordance with the previous report [15]. The finding of $75.8 \%$ of convalescent individuals testing positive for SARS-CoV antibody suggests the SARS antibody may disappear in some individuals who could later become reinfected.

To evaluate the effectiveness of the sandwich ELISA, 35 confirmed cases were also tested with real-time PCR. The results according to the stage of illness at which the sample was obtained are shown in Table 2. For samples from patients who had been ill for less than 10 days, the percentage detected by the sandwich ELISA was lower than that detected by real-time PCR. For the five sera collected more than 25 days after illness onset, the ELISA detected all five samples, while the real-time PCR detected only two. As for sera collected during the middle stage of illness (i.e., 10-25 days after illness onset), the two assays gave similar results of about $70 \%$.

Compared with real-time RT-PCR, the sandwich ELISA was less effective for detecting SARS-CoV during the early

Table 2 Comparison of results obtained using real-time PCR and the double-antigen sandwich ELISA to detect SARS in clinical samples of confirmed SARS patients

\begin{tabular}{llll}
\hline $\begin{array}{l}\text { Day of sample collection } \\
\text { after illness onset }\end{array}$ & No. of cases & \multicolumn{2}{l}{ No. $(\%)$ positive } \\
\cline { 2 - 4 } & & $\begin{array}{l}\text { Real-time } \\
\text { PCR }\end{array}$ & $\begin{array}{l}\text { Sandwich } \\
\text { ELISA }\end{array}$ \\
\hline $0-5$ & 5 & $3(60)$ & $1(20)$ \\
$6-10$ & 2 & $2(100)$ & $1(50)$ \\
$10-25$ & 23 & $15(82.6)$ & $18(78.2)$ \\
$>25$ & 5 & $2(40)$ & $5(100)$ \\
Total & 35 & $22(62.8)$ & $25(71.4)$ \\
\hline
\end{tabular}

stage of illness, but it was effective for detecting antibodies in patients who had been ill for more than 10 days. Our results indicate a combination of RT-PCR and ELISA would be the most effective means of detecting the SARS pathogen. In this trial, the percentage of cases detected by real-time PCR was unsatisfactory, even for samples obtained during the early stage of illness. This may be due to inefficient isolation of nucleic acid and nonstandard sampling that possibly resulted in reduced levels of RNA.

In our primary trials with protein microarray (data not shown), the nucleocapsid protein, especially the second half, which is located at 213aa-423aa of the C-terminal of this protein, showed strong antigenicity. Our use of this polypeptide as an antigen in the development of our double-antigen sandwich ELISA for detecting antibodies to SARS-CoV in serum was based on this finding. This double-antigen sandwich ELISA, which employs recombinant $\mathrm{N}$ protein as the serodiagnostic antigen and uses enzyme-conjugated antigen instead of enzyme-conjugated secondary antibody, provides a safe, specific, and sensitive means of detecting or confirming SARS infection.

Acknowledgments The authors would like to thank Prof. Li Ming at the Tropical Medical Research Institute of the First Military Medical University for the provision of antiserum from mouse vaccinated with the inactivated SARS coronavirus and all five hospitals mentioned in the paper for the provision of serum samples. This study was funded by the Hi-Tech Research and Development (863) Program of China, no. 2003AA208204

\section{References}

1. Ksiazek TG, Erdman D, Goldsmith CS, Zaki SR, Peret T, Emery S (2003) A novel coronavirus associated with severe acute respiratory syndrome. N Engl J Med 348:1953-1966

2. El-Sahly HM, Atmar RL, Glezen WP, Greenberg SB (2000) Spectrum of clinical illness in hospitalized patients with "common cold" virus infections. Clin Infect Dis 31:96-100

3. Rota PA, Oberste MS, Monroe SS, Nix WA, Campagnol R, Icenogle JP (2003) Characterization of a novel coronavirus associated with severe acute respiratory syndrome. Science 300:1394-1399

4. Kuo L, Masters PS (2002) Genetic evidence for a structural interaction between the carboxy termini of the membrane and nucleocapsid proteins of mouse hepatitis virus. J Virol 76:4987-4999

5. Narayanan K, Chen CJ, Maeda J, Makino S (2003) Nucleocapsid-independent specific viral RNA packaging via viral envelope protein and viral RNA signal. J Virol 77:2922-2927

6. Che XY, Qiu LW, Pan YX, Wen K, Hao W, Zhang LY, Wang YD, Liao ZY, Hua X, Cheng VC, Yuen KY (2004) Sensitive and specific monoclonal antibody-based capture enzyme immunoassay for detection of nucleocapsid antigen in sera from patients with severe acute respiratory syndrome. J Clin Microbiol 42:2629-2635

7. Guan M, Chen HY, Foo SY, Tan YJ, Goh PY, Wee SH (2004) Recombinant protein-based enzyme-linked immunosorbent assay and immunochromatographic tests for detection of immunoglobulin $\mathrm{G}$ antibodies to severe acute respiratory syndrome (SARS) coronavirus in SARS patients. Clin Diagn Lab Immunol 11:287-291

8. Woo PC, Lau SK, Wong BH, Tsoi HW, Fung AM, Chan KH (2004) Detection of specific antibodies to severe acute respiratory syndrome (SARS) coronavirus nucleocapsid protein for serodiagnosis of SARS coronavirus pneumonia. J Clin Microbiol 42:2306-2309 
9. Shi Y, Yi Y, Li P, Kuang T, Li L, Dong M, Ma Q, Cao C (2003) Diagnosis of severe acute respiratory syndrome (SARS) by detection of SARS coronavirus nucleocapsid antibodies in an antigen-capturing enzyme-linked immunosorbent assay. J Clin Microbiol 41:5781-5782

10. Liu X, Shi Y, Li P, Li L, Yi Y, Ma Q, Cao C (2004) Profile of antibodies to the nucleocapsid protein of the severe acute respiratory syndrome (SARS)-associated coronavirus in probable SARS patients. Clin Diagn Lab Immunol 11:227-228

11. Tan YJ, Goh PY, Fielding BC, Shen S, Chou CF, Fu JL (2004) Profiles of antibody responses against severe acute respiratory syndrome coronavirus recombinant proteins and their potential use as diagnostic markers. Clin Diagn Lab Immunol 11:362-371
12. Wilson MB, Nakane PK (1978) Recent developments in the periodate method of conjugating horseradish peroxidase (HRPO) to antibodies. Immunofluorescence and related staining techniques. North-Hollland Biomedical Press, Amsterdam, pp 215-224

13. Hermanson GT (1996) Bioconjugate techniques. Academic Press, San Diego, CA, pp 630-632

14. Chen SH, Zhang ML, Huang J, Bo XC, Wang SQ (2004) Development of real-time RT-PCR assay for the quantitation of SARSassociated coronavirus. Prog Biochem Biophys 31:249-254

15. Centers for Disease Control and Prevention (2003) Updated interim U.S. case definition of severe acute respiratory syndrome (SARS), CDC, Atlanta, GA. Available at http://www.cdc.gov/ncidod/sars/casedefinition.htm. Cited 23 July 2005 